\title{
NÍVEIS DE AMINOÁCIDOS NA DIETA DE SUÍNOS MACHOS INTEIROS DOS 25 AOS 70KG ${ }^{1}$
}

\author{
LEVELS OF AMINOACIDS IN DIET FOR BOARS FROM 25 AT 70KG
}

\section{Cezar Dobler Castagna $^{2}$ Paulo Alberto Lovatto ${ }^{3}$ Arlei Rodrigues Bonet de Quadros ${ }^{4}$ Silvana Pedroso 5}

\section{RESUMO}

No Brasil, o abate de suínos machos inteiros é proibido, mas esta categoria apresenta vantagens econômicas quando comparada a suínos machos castrados. Trabalhos têm demonstrado que existem diferenças no requerimento nutricional entre essas categorias. $O$ presente experimento foi realizado na Universidade Federal de Santa Maria, com o objetivo de analisar a interação de níveis diferenciados de aminoácidos, onde 96 animais foram avaliados quanto ao seu desempenho frente a dietas com 100, 90, 80 e $70 \%$ dos níveis máximos recomendados para lisina, treonina, metionina + cistina e triptofano $(1,25,0,81,0,75$ e 0,22\%, respectivamente), citados na literatura científica, dos 25 aos $70 \mathrm{~kg}$. Não foram observadas diferenças significativas $(P \geq$ $0,05)$ para consumo de ração, ganho de peso médio diário e conversão alimentar quando analisados no período integral, sendo que os níveis de 0,87\% de lisina, 0,57\% de treonina, 0,52\% de metionina + cistina e $0,16 \%$ de triptofano foram suficientes para garantir bom desempenho, apresentando maior economia entre os níveis testados.

Palavras-chave: nutrição, lisina, treonina, metionina, cistina, triptofano.

\section{SUMMARY}

In Brazil, the slaughter of boar is prohibited, however this category presents economic advantages when compared with the barrows. Some experiments have demonstrated that differences exist in the nutritional requirement among these categories. The present experiment was carried out at the Federal Universty of Santa Maria, where 96 animals were evaluated concerning performance when fed with diets containig 100, 90, 80 and 70\% of the maximum levels recommended for lysine, threonine, methionine + cystine and tryptophan (1.25, $0.81,0.75$ and $0.22 \%$, respectively) until they reached an average weight of $70 \mathrm{~kg}$. No significant differences $(P \geq 0.05)$ were observed for food intake, daily gain and feed conversion efficiency during the whole period, being the levels of $0.87 \%$ lysine, $0.57 \%$ threonine, $0.52 \%$ methonime + cystine and $0.16 \%$ tryptophan enough to provide good performance, and showed to be more economic between tested levels.

Key words: nutrition, lisyne, threonine, methionine, cystine, tryptophan, swine.

\section{INTRODUÇÃO}

No Brasil, o abate de suínos machos inteiros (MI) e com sinais de castração recente é proibido (Artigo 121 do Regulamento de Inspeção Sanitária e Industrial de Produtos de Origem Animal RISPOA). Isso implica perdas do ponto de vista econômico, pois estudos comprovam que a eficiência alimentar de machos inteiros é de aproximadamente 10 a $15 \%$ superior aos castrados, com melhor ganho de peso diário e com maior quantidade de carne magra na carcaça (FÁVERO, 1990). Por ser uma categoria de pouca expressão industrial, são poucas as informações técnicas em nosso País, para

\footnotetext{
${ }^{1}$ Trabalho integrante da Dissertação de Mestrado do primeiro autor, financiada por UFSM, CAPES e Frigorífico Prenda S.A.

2 Médico Veterinário, Curso de Pós-graduação em Zootecnia, Departamento de Zootecnia, Universidade Federal de Santa Maria (UFSM), 97105-900 Santa Maria, RS. E-mail: ccastagna @ hotmail.com. Autor para correspondência.

${ }^{3}$ Médico Veterinário, Professor do Departamento de Zootecnia, UFSM.

${ }^{4}$ Zootecnista, Professor do Departamento de Zootecnia, UFSM.

${ }^{5}$ Acadêmico do Curso de Zootecnia, UFSM.
} 
a determinação de níveis nutricionais ideais para a genética disponível. Os trabalhos existentes, na sua maioria, avaliam grandes frações alimentares, como por exemplo proteína bruta ou ainda energia, sem fazer uma análise mais profunda sobre a divisão das frações ou de seus níveis ideais, bem como a interação desses aminoácidos. Tendo em vista os pontos anteriormente citados, foi conduzido o presente experimento com o objetivo de avaliar o desempenho de MI frente a dietas com níveis diferenciados de aminoácidos.

A vantagem econômica que os MI têm sobre os castrados (MC) é bem relatada pela literatura científica, destacando principalmente maior ganho de peso (NUNES et al., 1980; SILVA et al., 1992; DONZELE $\boldsymbol{e t}$ al., 1993; DONZELE $\boldsymbol{e t}$ al., 1994), melhor conversão alimentar ou eficiência alimentar (NUNES $\boldsymbol{e t}$ al., 1980; WILLIAMS $\boldsymbol{e t}$ al., 1984; SILVA et al., 1992), maior carcaça (SKJAERLUND et al., 1994) e maior quantidade de carne magra (DONZELE $\boldsymbol{e t}$ al., 1993; SKJAERLUND $\boldsymbol{e t} \boldsymbol{a l}$, 1994). Essa categoria animal pode chegar ao peso de abate de 12 a 16 dias antes que as demais (SILVA $\boldsymbol{e t}$ $\boldsymbol{a l} .$, 1992); isso significa uma redução de 8 a $11 \%$ do período total que o animal permanece na granja, acarretando uma maior competitividade econômica. Com todas essas diferenças, é esperado que as necessidades ou requerimentos de nutrientes sejam diferentes em alguns pontos, como já demonstraram NUNES et al. (1980), WILLIAMS et al. (1984) e DONZELE et al. (1994). Apesar disso, as tabelas de exigências nacionais e estrangeiras, por ocasião da realização do presente experimento, não forneciam as necessidades de energia, proteína bruta (PB) e aminoácidos para diferentes sexos e/ou categorias (WILLIAMS et al., 1984; DONZELE $\boldsymbol{e t}$ al., 1994) e, como agravante, existem trabalhos que demonstram que os requerimentos encontrados foram superiores aos que constam nessas tabelas (HAHN et al. 1995). O lançamento de novas tabelas estrangeiras, posterior à realização desse trabalho, começa a explanar com mais precisão essas diferenças, embora dúvidas quanto a interação de aminoácidos, permaneçam.

As formulações utilizadas para confecção de rações de suínos têm como principais ingredientes grãos de milho, soja e seus subprodutos. $\mathrm{O}$ milho possui acentuada deficiência em lisina e triptofano, enquanto outros cereais como sorgo, cevada e trigo (eventuais substitutos) são deficientes em lisina e treonina. Para a soja, o aminoácido limitante é a metionina tornando, na prática, lisina, metionina, treonina e triptofano os aminoácidos que merecem maior atenção na nutrição de suínos (FRASER, 1986). Com a introdução de aminoácidos cristalinos na ração (principalmente lisina, treonina e DLmetionina), esses níveis podem ser atingidos com a redução da PB na dieta, tornando o preço da ração mais competitivo, sem afetar o desempenho do animal como também a qualidade da carcaça (HAHN $\boldsymbol{e t}$ al., 1995; HAHN \& BAKER, 1995).

A lisina é o primeiro aminoácido limitante para suínos alimentados com dietas baseadas em milho e farelo de soja (MOITA et al., 1994; HAHN et al., 1995; GODOY et al., 1996; TUITOEK et al., 1997). Vários estudos já foram realizados com o objetivo de determinar as quantidades de lisina para as diferentes fases da vida de suínos, porém, é grande a amplitude de valores considerados ideais para crescimento e terminação, como por exemplo 0,39 (FRASER, 1986) ou 1,25\% (FULLER \& CHAMBERLAIN, 1985). HAHN et al. (1995) citam que fatores específicos afetam o requerimento de lisina como: genética, sexo, critério avaliado, concentração de energia na dieta, biodisponibilidade da lisina, freqüência da alimentação e método estatístico utilizado, além de outros fatores, como densidade populacional, temperatura e nível de doenças. Esses fatores, provavelmente, irão influenciar o requerimento dos demais aminoácidos essenciais. A metionina, juntamente com a lisina, são os dois principais aminoácidos limitantes para suínos (MOITA et al., 1996) e, novamente, foram encontradas grandes diferenças no requerimento de metionina - cistina, variando de 0,23\% (FRASER, 1986) até 0,75\% (MOITA et al., 1996), lembrando que esses valores não fazem referência ao efeito do sexo sobre o requerimento de aminoácidos. Segundo SALDANA $\boldsymbol{e t}$ al. (1994), a treonina é normalmente o $2^{\circ}$ ou $3^{\circ}$ aminoácido limitante em dietas de suínos e pode ser o primeiro quando é adicionada lisina cristalina. A literatura científica cita como requerimento de triptofano desde 0,08 (FRASER, 1986) até 0,22\% (FULLER \& CHAMBERLAIN, 1985).

\section{MATERIAL E MÉTODOS}

O presente experimento foi desenvolvido no Setor de Suinocultura, do Departamento de Zootecnia, da Universidade Federal de Santa Maria, localizado em Camobi, município de Santa Maria RS, com latitude $53^{\circ} 43^{\prime}$ Sul e longitude $29^{\circ} 42^{\prime}$, ficando a 95 metros de altitude. O início ocorreu no dia 07 de outubro de 1996 e o término, no dia 09 de dezembro do mesmo ano. Durante os meses citados, a temperatura média foi de $22,2^{\circ} \mathrm{C}$, com média das temperaturas máximas em $27,8^{\circ} \mathrm{C}$, e média das temperaturas mínimas em $17,5^{\circ} \mathrm{C}$.

Foram utilizados 96 suínos machos inteiros "tri cross" \{F1 (Landrace x Large White) x 
Duroc\}, em final de creche com peso inicial médio de $25,26 \mathrm{~kg}$ e idade média de 64 dias, oriundos de criação comercial. Os animais foram alojados em um galpão experimental com $35,00 \times 8,00 \times 2,45 \mathrm{~m}$, com cobertura de telhas de cimento amianto e piso de concreto. Essa estrutura abrigava a creche, a unidade de crescimento e terminação e o depósito de ração. A unidade de crescimento e terminação era subdividida em 24 baias de 3,20 x 1,40 x 0,90m, e com $3 \%$ de declividade. Na porção anterior de cada baia, encontrava-se um comedouro de acesso único, conjugado com bebedouro tipo chupeta no alimentador, o qual proporcionou o fornecimento de ração ad libitum, sendo que as porções de ração fornecidas para cada lote foram pesadas previamente. Sabendo-se que MI necessitam de um aporte maior de nutrientes, em especial de proteína bruta na dieta (NUNES et al., 1980), foi seguida a orientação de FULLER \& CHAMBERLAIN (1985), que recomendam os níveis máximos de aminoácidos para suínos em crescimento, a partir dos quais foram elaboradas 4 dietas com níveis diferenciados de aminoácidos, cujos valores estão expostos na Tabela 1. O tratamento 1 ( $\mathrm{T} 1$ ) representa $100 \%$ dos níveis máximos recomendados de lisina, treonina, metionina + cistina e triptofano, e os tratamentos 2 , 3 e 4 (T 2, T 3 e T 4), representam 90, 80 e 70\% dos valores do $\mathrm{T} 1$, respectivamente. As dietas foram isoproteicas e isoenergéticas.

Os animais foram agrupados em blocos de acordo com o seu peso, de tal forma que os tratamentos fossem representados por 24 animais, distribuídos em 6 repetições, sendo que cada unidade experimental era formada por 4 animais. No primeiro dia, foi realizada a pesagem (balança com capacidade para $150 \mathrm{~kg}$ e precisão de $0,1 \mathrm{~kg}$ ) e a identificação dos animais por meio de brinco. As pesagens repetiram-se a cada 14 dias e, ao final de cada pesagem rotineira, foi realizada uma estimativa através do ganho de peso médio diário, quanto aos dias para que o grupo (repetição) atingisse o peso de $70 \mathrm{~kg}$, ocasião em que foi realizada a pesagem final de cada repetição. Antes de cada pesagem houve uma restrição alimentar de 12 horas. Os pesos obtidos durante as diferentes pesagens, assim como o consumo alimentar, geraram outros dados, como o ganho de peso médio diário, consumo alimentar médio diário e conversão alimentar. Os dados referentes ao custo e formulação de rações encontram-se na Tabela 2 de onde foi possível calcular o custo médio da ração consumida por cada animal, assim como o custo (em ração) do $\mathrm{kg}$ de suíno produzido, conforme as seguintes equações:

$$
\text { Custo da ração consumida: } \sum \underset{i=j}{(\text { CPP }) . ~ P P R ~}
$$

Onde: $\mathrm{CPP}=$ Consumo de ração no período;

PPR = Preço por kg de ração (conforme Tabela 2).

Custo do kg de suíno (em ração) $=$ CAT . PPR

Onde CAT $=$ Conversão alimentar calculada sobre toda a duração do experimento. $\mathrm{PPR}=$ Preço por $\mathrm{kg}$ de ração.

Todas as variáveis foram submetidas à análise de variância e regressão pelo pacote estatístico SAS (1992). Como procedimentos complementares, foi realizada a higienização das baias, que constou da raspagem diária dos dejetos, como também limpeza do acesso do comedouro quando houve necessidade.

\section{RESULTADOS E DISCUSSÃO}

Os níveis de aminoácidos usados para esse experimento não tiveram amplitude suficiente para promover uma diferenciação $(P \geq 0,05)$ nas respostas para consumo alimentar em nenhum dos períodos, assim como no total do experimento, como mostra a Tabela 3. Os resultados concordam com os de TUITOEK et al. (1997), os quais afirmam que animais alimentados com suplementação de aminoácidos cristalinos não apresentam diferenças no consumo. O ganho de peso médio diário também não apresentou diferenças $(\mathrm{P} \geq 0,05)$, assim como os pesos nos diferentes períodos do experimento. A conversão alimentar como um todo também seguiu o comportamento das demais variáveis dependentes, não apresentan-

* Níveis de aminoácidos em relação ao máximo recomendado pela bibliografia consultada. 
Tabela 2 - Formulações das rações utilizadas no experimento nutricional.

\begin{tabular}{|c|c|c|c|c|c|}
\hline \multirow[b]{2}{*}{ Ingredientes } & \multirow{2}{*}{$\begin{array}{l}\text { Custo/kg } \\
\text { do } \\
\text { ingrediente }\end{array}$} & \multicolumn{4}{|c|}{ Tratamentos / \% de ingredientes utilizados } \\
\hline & & T $1(100 \% *)$ & T $2(90 \% *)$ & T $3(80 \% *)$ & T $4(70 \% *)$ \\
\hline Milho moído & 0,1500 & 78,41 & 77,49 & 76,45 & 75,83 \\
\hline F. de soja (46) & 0,3900 & 11,40 & 11,80 & 12,40 & 12,80 \\
\hline F. de trigo & 0,1200 & 6,30 & 7,20 & 8,00 & 8,60 \\
\hline Fosfato bicálcico & 0,4500 & 1,20 & 1,20 & 1,20 & 1,20 \\
\hline Calcário & 0,1000 & 0,6000 & 0,6000 & 0,6000 & 0,6000 \\
\hline Lisina & 2,6600 & 0,4920 & 0,4490 & 0,4190 & 0,3200 \\
\hline Triptofano & 5,0000 & 0,4233 & 0,2611 & 0,1008 & --- \\
\hline Sal moído & 0,1000 & 0,4000 & 0,4000 & 0,4000 & 0,4000 \\
\hline Metionina & 4,4800 & 0,2959 & 0,1940 & 0,1160 & 0,0280 \\
\hline Treonina & 5,0000 & 0,2820 & 0,2031 & 0,1111 & 0,0179 \\
\hline Premix vitamínico & 3,2000 & 0,1000 & 0,1000 & 0,1000 & 0,1000 \\
\hline Premix mineral & 0,8900 & 0,1000 & 0,1000 & 0,1000 & 0,1000 \\
\hline Custo da ração (R\$) & --- & 0,2418 & 0,2252 & 0,2101 & 0,1951 \\
\hline
\end{tabular}

Sugestão de Formulação: PROVIMI S/A Nutrição Animal.

* Níveis de aminoácidos em relação ao máximo recomendado pela bibliografia consultada.

que pode ter auxiliado para que não houvesse maior diferenciação entre os tratamentos é que a menor quantidade de aminoácidos testados, representados pelo $\mathrm{T} 4$, está acima dos valores considerados mínimos por WILLIAMS et al. (1984), SALDANA et al. (1994) e TUITOEK et al. (1997). Confirmando esse fato, autores como TUITOEK et al. (1997), HAHN et al. (1995) e WILLIAMS et al. (1984) verificaram que os níveis de 0,71, 0,77 e $0,74 \%$ de lisina, respectivamente, são suficientes para atender as exigências de MC de idades semelhantes ou inferiores às testadas nesse experimento. Assim, esses ní-

do diferença estatística ( $\mathrm{P} \geq 0,05)$, conforme a Tabela 3. As análises de regressão, tanto para consumo total de ração como para ganho de peso médio diário total, peso final e conversão alimentar total, não apresentaram efeito linear ou quadrático $(\mathrm{P} \geq 0,05)$, baseados na percentagem de lisina na ração.

É difícil fazer uma comparação com os demais trabalhos descritos na literatura científica, uma vez que, em grande parte, todos tratam os aminoácidos separadamente, e, raramente, com esses variando na mesma proporção. De acordo com KERR \& EASTER (1995), não se deve pesquisar o requerimento de um aminoácido isoladamente, devido à inter-relação que pode ter com os demais, o que traz a necessidade da condução de novos trabalhos, com o intuito de aumentar o conhecimento sobre as inter-relações dos principais aminoácidos limitantes para suínos em crescimento/terminação. Outro fator veis são inferiores aos testados, não atingindo um limite suficiente para causar influência no desempenho de MI, que, teoricamente, estaria mais elevado do que para as demais categorias.

Trabalhos desenvolvidos apresentam resultados diferentes aos do presente experimento, quanto à influência de aminoácidos no consumo (MOITA et al., 1994; SALDANA et al., 1994), ganho de peso (MOITA et al., 1994; HAHN $\boldsymbol{e t}$ al., 1995) e conversão ou eficiência alimentar (HAHN et al., 1995; HAHN \& BAKER, 1995), embora, na sua maioria, os autores tenham trabalhado com níveis diferentes de aminoácidos, ou sem a presença de MI. Aliado a esse fato, juntam-se os critérios que podem influenciar o requerimento de lisina descritos por HAHN et al. (1995) citados anteriormente. Também deve-se levar em consideração que níveis elevados

Tabela 3 - Consumo de ração médio diário, ganho de peso médio diário, peso final, conversão alimentar média, custo da ração consumida e custo do kg de suínos machos inteiros alimentados com dietas contendo níveis diferenciados de aminoácidos.

\begin{tabular}{|c|c|c|c|c|c|}
\hline & $\mathrm{T} 1(100 \% *)$ & T2 $(90 \% *)$ & T3 $(80 \% *)$ & $\mathrm{T} 4(70 \% *)$ & Probabilidade \\
\hline Consumo (kg) & $2,29 \pm 0,23$ & $2,39 \pm 0,26$ & $2,33 \pm 0,19$ & $2,22 \pm 0,21$ & 0,6108 \\
\hline Peso final (kg) & $70,81 \pm 3,50$ & $71,829 \pm 3,20$ & $69,987 \pm 1,99$ & $67,596 \pm 6,21$ & 0,3352 \\
\hline Custo da ração consumida ( $\mathrm{R} \$$ ) & $28,36^{\mathrm{a}}$ & $27,45^{\mathrm{a}}$ & $25,02^{\mathrm{ab}}$ & $21,99^{\mathrm{b}}$ & 0,0003 \\
\hline Custo do kg de suíno em ração (R\$) & $0,62^{\mathrm{a}}$ & $0,59^{\mathrm{a}}$ & $0,56^{\mathrm{ab}}$ & $0,52^{\mathrm{b}}$ & 0,0012 \\
\hline
\end{tabular}


de aminoácidos podem estar relacionados com uma possível redução na energia líquida disponível para o animal, associada com um provável aumento na excreção de nitrogênio urinário (DONZELE $\boldsymbol{e t} \boldsymbol{a l}$., 1994). KERR \& EASTER (1995) citam que com o aumento de 6 gramas no consumo de proteína além do requerido, somente $30 \%$ será retido, e o restante será excretado pelo rim, com perda direta de energia.

Os animais utilizados neste experimento eram provenientes de uma genética de uso comum em integrações comerciais, não sendo, portanto, de linhagens mais especializadas para produção de carne. Caso as linhagens fossem melhoradas, provavelmente o requerimento dos aminoácidos estaria alterado, onde poderiam ser observadas diferenças entre os tratamentos utilizados.

Quando a análise foi realizada, levando-se em consideração os custos de produção de acordo com o preço da ração, o quadro começou a definirse, com clara vantagem aos tratamentos que continham menores níveis de aminoácidos. Isso se deve ao fato de que o uso desses encarece o custo final da ração e, como não houve diferenças no desempenho, esses resultados já eram esperados. A Tabela 3 apresenta os dados referentes ao custo da ração, sendo que as equações da análise de regressão, baseadas na percentagem de lisina inclusa na ração, estão ilustradas nas Figuras 1 a 3.

\section{CONCLUSÕES}

Os dados obtidos no presente experimento nos permitem concluir que os níveis de aminoácidos

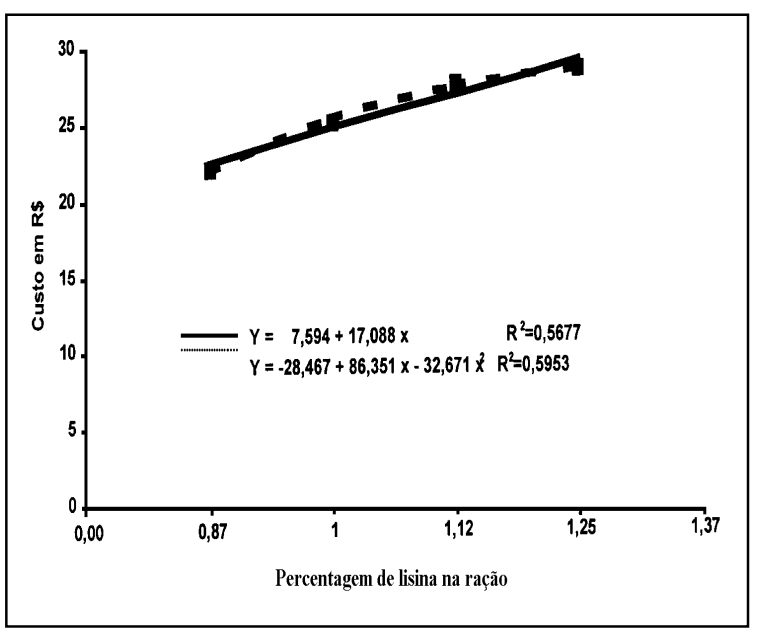

Figura 1 - Efeitos linear e quadrático da percentagem de lisina e demais aminoácidos testados sobre o custo da ração consumida por suíno macho inteiro, alimentado com dietas contendo níveis diferenciados de aminoácidos.

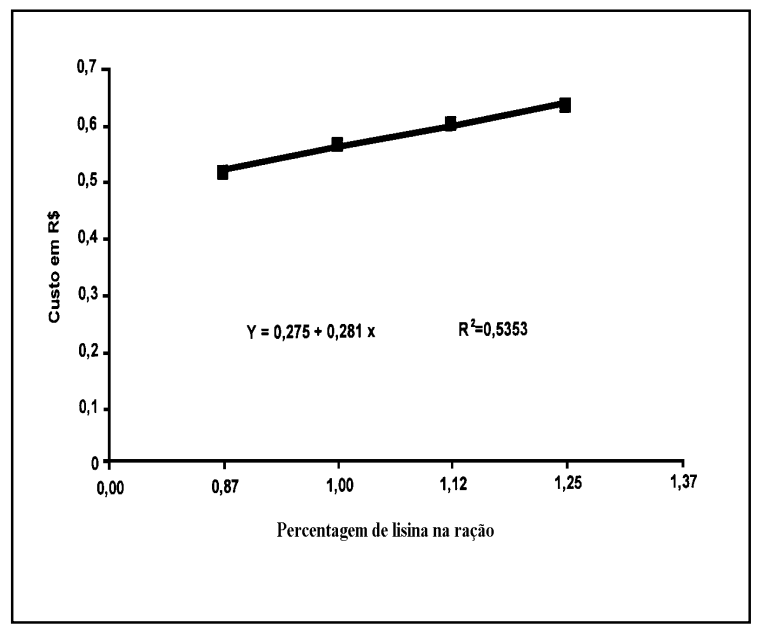

Figura 2 - Efeito linear da percentagem de lisina e demais aminoácidos testados sobre o custo do $\mathrm{kg}$ de suíno macho inteiro alimentado com dietas contendo níveis diferenciados de aminoácidos.

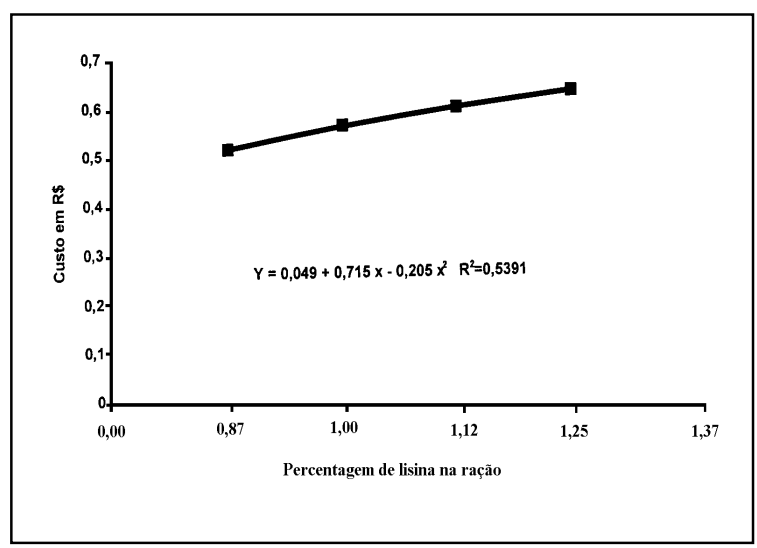

Figura 3 - Efeito quadrático da percentagem de lisina e demais aminoácidos testados sobre o custo do $\mathrm{kg}$ de suíno macho inteiro alimentado com dietas contendo níveis diferenciados de aminoácidos.

estudados atendem as necessidades de suínos machos inteiros nas fases de crescimento e terminação, não havendo amplitude suficiente para influenciar no ganho de peso, conversão alimentar e consumo. Os níveis de $0,87 \%$ de lisina, $0,57 \%$ de treonina, $0,52 \%$ de metionina + cistina e $0,16 \%$ de triptofano são suficientes para desempenho de suínos machos inteiros para as fases de crescimento e terminação, em um nível de $3.200 \mathrm{kcal} / \mathrm{kg}$ de energia metabolizável, determinando uma maior economia em custo de alimentação do que as demais proporções estudadas. $O$ requerimento e a interação de aminoácidos fornecidos para suínos machos inteiros, durante as fases 
de crescimento e terminação, merecem novos estudos, devido ao crescente interesse econômico desta categoria.

\section{REFERÊNCIAS BIBLIOGRÁFICAS}

DONZELE, J.L., FREITAS, R.T.F., LOPES, D.C. Níveis de proteína bruta para suínos machos inteiros dos 30 aos $60 \mathrm{~kg}$ de peso vivo. Revista da Sociedade Brasileira de Zootecnia, v. 22, n. 2, p. 287-292, 1993.

DONZELE, J.L., PAULA, T.A.R., FREITAS, R.T.F., $\boldsymbol{e} \boldsymbol{t}$ al. Níveis de proteína para suínos machos inteiros, dos 60 aos $100 \mathrm{~kg}$ de peso vivo. Revista da Sociedade Brasileira de Zootecnia., v. 23, n. 4, p. 642-654, 1994.

FÁVERO, J.A. Tipificação de carcaças de suínos e seus reflexos na produção, na industrialização e no consumo. Suinocultura. Sociedade Brasileira de Zootecnia. Campinas, São Paulo, 1990.

FRASER, C.M., Manual Merck de Veterinária. Parte V- Manejo, criação e nutrição. 6. ed., São Paulo: Roca, 1986.

FULLER, M.F., CHAMBERLAIN, A.G. Protein requeriments of pigs. Recente developments in pig nutrition. Butterworths, Londres, 1985

GODOY, M.L., DONZELE, J.L., FERREIRA, A.S., et al. Níveis de energia para suínos machos inteiros dos 30 aos $60 \mathrm{~kg}$. Revista da Sociedade Brasileira de Zootecnia, v. 25, n. 6 , 1996.

HAHN, J.D., BAKER, D.H. Optimum ratio to lysine of threonine, triptofan, and sulfur amino acids for finishing swine. Journal of Animal Science, v. 73, p. 482-489, 1995.

HAHN, J.D., BIEHL, R.R., BAKER, D.H. Ideal digestible lysine level for early- and late-finishing swine. Journal of Animal Science, v. 73, p. 773-784, 1995.
KERR, B.J., EASTER, R.A. Effect of feeding reduced protein, amino acid-supplemented diets on nitrogen and energy balance in grower pigs. Journal of Animal Science, v. 73, p. 3000-3008, 1995.

MOITA, A.M.S., COSTA, P.M.A., DONZELE, J.L. Exigências de metionina + cistina, por leitões de 12 a 28 dias de idade. Revista da Sociedade Brasileira de Zootecnia, v. 25, n. 3 , p. 494-500, 1996

MOITA, A.M.S., COSTA, P.M.A., DONZELE, J.L., et al. Exigências de lisina de leitões por 12 a 28 dias de idade. Revista da Sociedade Brasileira de Zootecnia, v. 23, n. 5, p. 803$812,1994$.

NUNES, J.R.V., LÓPEZ, J., NICOLAIEWSKY, S. Desempenho e características da carcaça de machos inteiros e castrados sob dietas com dois níveis de proteína. Revista da Sociedade Brasileira de Zootecnia, v. 9, n. 1, p. 1-9, 1980

SALDANA, C.I., KNABE, D.A., OWEN, K.Q., et al. Digestible threonine requirements of starter and finisher pigs. Journal of Animal Science., v. 72, p. 144-150, 1994.

SILVA, M.A., CATALAN, G., TORRES, R.A., et al. Fatores que influem no desempenho de suínos das raças Landrace, Large White e Duroc. I. Características produtivas. Revista da Sociedade Brasileira de Zootecnia, v. 21, n. 5, p. 912-922, 1992

SKJAERLUND, D.M., MULVANEY, D.R., BERGEN, W.G., $\boldsymbol{e}$ al. Skeletal muscle growth and protein turnover in neonatal boars and barrows. Journal of Animal Science, v. 72, p. 315-321, 1994.

TUITOEK, K., YOUNG, L.G., LANGE, C.F.M., et al. The effect of reducing excess dietary amino acids on growing-finishing pig performance: an evaluation of the ideal protein concept. Journal of Animal Science, v. 75, p. 1575-1583, 1997.

WILLIAMS, W.D., CROMWELL, G.L., STAHLY, T.S., et al. The lysine requirement of the growing boar versus barrow. Journal of Animam Science., v. 58, n. 3, p. 567-665, 1984. 